\title{
Response to comment on "Oestrogen- induced angiogenesis and implantation contribute to the development of parasitic myomas after laparoscopic morcellation"
}

Ben-Shian Huang ${ }^{1,2,3,4}$, Huann-Cheng Horng ${ }^{1,3}$, Peng-Hui Wang ${ }^{1,3,4}$, Muh-Hwa Yang ${ }^{4}$ and Yi-Jen Chen 1,3,4,5*

\begin{abstract}
According to the literature review, $\mathrm{CO} 2$ insufflation on parasitic myoma implantation is not well studied, and we concur that our study is related to "Morcellation-induced parasitic myomas." We did not compare CO2 insufflation to non-insufflation in our study. The reason is the efficacy of gasless laparoscopic myomectomy and morcellation is not well established and this modality is seldom performed. Moreover, the effects of pneumoperitoneum on mesothelial cells and the role of the entire peritoneal cavity as a cofactor in adhesion formation have become well established, the role of $\mathrm{CO} 2$ insufflation in the establishment of parasitic myomas has not yet been studied. As such, more in-depth and well-designed studies for the role of $\mathrm{CO} 2$ insufflation are needed.
\end{abstract}

\section{Response}

We appreciate the interest in our manuscript by Mynbaev et al. [1] but find the criticism debatable. We concur that the heterogeneity of myomas, even from the same uterus, can have different mutations and diverse features depending on their size and location (submucosal, intramural and subserosal). In addition, we also concur with another view of the myoma pseudo-capsule, which consists of a fibroneuro-vascular network and initiates angiogenesis and vascularization in the myomas. In this study, we received Ethics approval and consent to participate as well as for publication from the patients in our original article (VGHIRB No 2014-10-002C for human tissue; IACUC 2014-119 for animal study). We only used the intramural type of myoma and the central part of myoma tissue, which reduced the issue of heterogeneity of uterine myomas. Moreover, before each xenograft procedure in our study, we mixed myoma specimens obtained from two patients. The

\footnotetext{
*Correspondence: chenyj@vghtpe.gov.tw; chenyj58@gmail.com

'Department of Obstetrics and Gynaecology, Taipei Veterans General

Hospital, No.201, Sec. 2, Shih-Pai Road, Taipei 112, Taiwan

${ }^{3}$ Department of Obstetrics and Gynaecology, School of Medicine, No.155,

Sec.2, Li-Nong Street, Taipei 112, Taiwan

Full list of author information is available at the end of the article
}

myoma fragments were cultured with E2-containing medium, which provided consistency of the oestrogen effect before xenotransplantation to eliminate individual differences in systemic/local oestrogen levels. Uterine myoma is also known as an oestrogendependent disorder, and myomas from women in different phases might present different systemic/local oestrogen levels. In addition, the tissue fragments, which were 1-2 $\mathrm{mm}^{3}$ in size, were manipulated aseptically at room temperature; but a culture time of more than $4 \mathrm{~h}$ may be associated with lower viability of the implanted tissue fragments in the in vivo study $[2,3]$. This xenograft mouse model has been established.

According to the literature review, $\mathrm{CO}_{2}$ insufflation on parasitic myoma implantation is not well studied, and we concur that our study is related to "Morcellation-induced parasitic myomas." We did not compare $\mathrm{CO} 2$ insufflation to non-insufflation in our study. The reason is the efficacy of gasless laparoscopic myomectomy and morcellation is not well established and this modality is seldom performed $[4,5]$.

The pathophysiology of adhesion formation is traditionally considered a local phenomenon resulting from surgical trauma to the peritoneal surfaces, as well 
as involving the basal membrane, mesothelial cells, and sub-endothelial connective tissue. This leads to a local inflammatory reaction and a cascade of events, such as exudation, fibrin deposition, and capillary growth at the site of injury [6]. Moreover, postoperative adhesion increases with desiccation and with the duration and pressure of carbon dioxide $\left(\mathrm{CO}_{2}\right)$ pneumoperitoneum by insufflation through a subnormal mesothelial partial $\mathrm{O}_{2}$ pressure. It increases if the pneumoperitoneum contains more than $10 \% \mathrm{O}_{2}$ through a supernormal mesothelial partial $\mathrm{O}_{2}$ pressure and reactive $\mathrm{O}_{2}$ species (ROS) [7]. Evidence of decreased acute inflammation includes the prevention of desiccation by humidified gas, gentle tissue handling as evidenced by the decreasing adhesions during the learning curve, and a physiologic mesothelial partial $\mathrm{O}_{2}$ pressure of approximately $30 \mathrm{mmHg}$ by adding $4 \% \mathrm{O}_{2}$ and/or $10 \%$ nitrous oxide $\left(\mathrm{N}_{2} \mathrm{O}\right)$ to the $\mathrm{CO}_{2}$ pneumoperitoneum [8-10]. However, the abovementioned postoperative adhesion mouse model was very different from that used in our study. Binda et al. have conducted excellent studies examining the association between artificial bipolar lesions and $\mathrm{CO}_{2}$ pneumoperitoneum by insufflation [7-10]. In the model we used, there was only a $1-\mathrm{cm}$ wound created, and we avoided manipulations to minimize tissue injury during xenograft procedures. Pneumoperitoneum was simulated by a pneumoperitoneum needle (Surgineedle ${ }^{\mathrm{tm}}$, Covidien, US) inserted into the abdominal cavity. The $\mathrm{CO}_{2}$ insufflation pressure was $4 \mathrm{mmHg}$, and the duration of insufflation was $10 \mathrm{~min}$ [11].

Although the effects of pneumoperitoneum on mesothelial cells and the role of the entire peritoneal cavity as a cofactor in adhesion formation have become well established, the role of $\mathrm{CO}_{2}$ insufflation in the establishment of parasitic myomas has not yet been studied. As such, more in-depth and well-designed studies for the role of $\mathrm{CO}_{2}$ insufflation are needed.

\section{Acknowledgments}

Not applicable.

\section{Funding}

This work was supported in part by the Ministry of Science and Technology (MOST 104-2314-B-075-022, MOST 104-2314-B-075-058 and MOST 1052314-B-075 -038 -MY2), Taipei Veterans General Hospital (VGH-103C-040, VGH-103-EA-020, VGH-104C-042, VGH-104-EA-0012 V105C-061, V105EP-002, and VN105-13), Yen-Tjing-Ling Medical Foundation (Cl-104-15 and Cl-104-14) and National Yang-Ming University Hospital (RD 2015-024 and RD 2016-016) and Szu-Yuan research foundation of internal medicine (105002).

\section{Availability of data and materials}

Not applicable.

\section{Authors' contributions}

BS-H and YJ-C wrote this response. All authors read and approved of the final manuscript.

\section{Competing interests}

The authors declare that they have no competing interest.

\section{Consent for publication}

In this response, there is no involvement of human tissue or animal study which demands Ethics approval. In our original article [1], we received Ethics approval and consent to participate as well as for publication from the patients, and the aforementioned consent forms are written in our official language-Chinese.

\section{Ethics approval and consent to participate}

In this response, there is no involvement of human tissue or animal study which demands Ethics approval. In our original article [1], the protocol was approved by the local ethics committee of the Institutional Review Board (IRB) of Taipei Veteran General Hospital (VGHIRB No 2014-10-002C for human tissue; IACUC 2014-119 for animal study).

\section{Publisher's note}

Springer Nature remains neutral with regard to jurisdictional claims in published maps and institutional affiliations.

\section{Author details}

${ }^{1}$ Department of Obstetrics and Gynaecology, Taipei Veterans General Hospital, No.201, Sec. 2, Shih-Pai Road, Taipei 112, Taiwan. ${ }^{2}$ Department of Obstetrics and Gynaecology, National Yang-Ming University Hospital, No.152, Xin-Min Road, Yilan 260, Taiwan. ${ }^{3}$ Department of Obstetrics and Gynaecology, School of Medicine, No.155, Sec.2, Li-Nong Street, Taipei 112 , Taiwan. ${ }^{4}$ Institute of Clinical Medicine, National Yang-Ming University, No.155, Sec.2, Li-Nong Street, Taipei 112, Taiwan. ${ }^{5}$ Department of Obstetrics and Gynaecology, Cheng-Hsin General Hospital, No.45, Cheng Hsin St., Pei-Tou, Taipei, Taiwan.

Received: 18 May 2017 Accepted: 17 June 2017

Published online: 20 July 2017

\section{References}

1. Huang BS, Yang MH, Wang PH, Li HY, Chou TY, Chen YJ. Oestrogen-induced angiogenesis and implantation contribute to the development of parasitic myomas after laparoscopic morcellation. Reprod Biol Endocrinol. 2016;14:64.

2. Chen YJ, Li HY, Huang CH, Twu NF, Yen MS, Wang PH, Chou TY, Liu YN, Chao KC, Yang MH. Oestrogen-induced epithelial-mesenchymal transition of endometrial epithelial cells contributes to the development of adenomyosis. J Pathol. 2010;222:261-70.

3. Huang TS, Chen YJ, Chou TY, Chen CY, Li HY, Huang BS, Tsai HW, Lan HY, Chang $\mathrm{CH}$, Twu NF, et al. Oestrogen-induced angiogenesis promotes adenomyosis by activating the slug-VEGF axis in endometrial epithelial cells. J Cell Mol Med. 2014;18:1358-71.

4. Takeda A, Imoto S, Mori M, Yamada J, Nakamura H. Isobaric two-port laparoscopic-assisted myomectomy by combined approach through umbilical and suprapubic mini-incisions with hidden scar: a technique and initial experience. Eur J Obstet Gynecol Reprod Biol. 2012;160:88-92.

5. Sesti F, Pietropolli A, Sesti FF, Piccione E. Uterine myomectomy: role of gasless laparoscopy in comparison with other minimally invasive approaches. Minim Invasive Ther Allied Technol. 2013;22:1-8.

6. diZerega GS, Campeau JD. Peritoneal repair and post-surgical adhesion formation. Hum Reprod Update. 2001;7:547-55.

7. Binda MM, Molinas CR, Bastidas A, Koninckx PR. Effect of reactive oxygen species scavengers, antiinflammatory drugs, and calcium-channel blockers on carbon dioxide pneumoperitoneum-enhanced adhesions in a laparoscopic mouse model. Surg Endosc. 2007;21:1826-34

8. Binda MM, Molinas CR, Hansen P, Koninckx PR. Effect of desiccation and temperature during laparoscopy on adhesion formation in mice. Fertil Steril. 2006;86:166-75.

9. Corona R, Verguts J, Binda MM, Molinas CR, Schonman R, Koninckx PR. The impact of the learning curve on adhesion formation in a laparoscopic mouse model. Fertil Steril. 2011;96:193-7.

10. Corona R, Binda MM, Mailova K, Verguts J, Koninckx PR. Addition of nitrous oxide to the carbon dioxide pneumoperitoneum strongly decreases adhesion formation and the dose-dependent adhesiogenic effect of blood in a laparoscopic mouse model. Fertil Steril. 2013;100:1777-83.

11. Carter JJ, Feingold DL, Kirman I, Oh A, Wildbrett P, Asi Z, Fowler R, Huang E, Whelan RL. Laparoscopic-assisted cecectomy is associated with decreased formation of postoperative pulmonary metastases compared with open cecectomy in a murine model. Surgery. 2003;134:432-6. 